\title{
A EQUIPE DE ENFERMAGEM FRENTE À PROBLEMÁTICA DA ASSISTEENCIA INDIVIDUALIZADA AO PACIENTE TERMINAL
}

\author{
Marta Lucia Carvalho Cheida ${ }^{1}$, Diva A. S. Christófolli²
}

\begin{abstract}
RESUMO. As autoras realizaram um estudo no Hospital Professor Antonio Prudente, na cidade de Londrina-PR, especializado no atendimento a pacientes oncológicos, buscando identificar conceitos e reações da equipe de enfermagem frente a esse tipo de paciente, considerado terminal. As pesquisadoras também tentaram identificar qual a área de necessidades humanas considerada prioritária na atuação deṣ equipe. Procurou-se, ainda, definir as reações frente ao cyento morte, reações essas que, no entender das autoras, influem no tipo de assistência prestada.
\end{abstract}

ABSTRACT. The authors developed a study at Professor Antonio Prudente Hospital, a cancer hospital in the city of Londrina-PR, trying to identify concepts and reactions of the nursing team in relation to those patients, considered terminal ones. The researchers also tried to identify which area of human needs was considered priority in team pertormance. Definition of nursing team reactions facing death was studied and the authors assume they do influence type of nursing care given.

\section{INTRODUÇÃO}

$\Lambda$ Linlomingem, segundo IIOR'la (1979), pode ser delinida como "a ciència e a arte de assistir o ser humano no atendimento de suas necessidades baísicas...". De acordo com essal tcoria, as necessidades básicals do homem sc classificam, inspirado em Mohana, em três grandes áreas: psicobiológicas, psicossociais e psicoespirituais, as quais são inter-relacionadas e independentes.

O ser humano, no entendimento de BASTOS (1983), deve ser analisado e compreendido como expressão de seus três planos: a) Um plano físico, vital, somático, orgânico;

b) Um planno psicossocial, onde ele vive e se relacionlia;

c) Un plano existencial (de valores pessuais) mediante o qual ele compreende e direciona sua existência.

$\mathrm{O}$ autor considera esses três planos como "manifestações distintas de um mesmo fenômeno ou diferentes ângulos da mesma realidade".

Esse não tão novo enfoque do indivíduo como um todo indivisível inspira um movimento na área da saúde, assim como em outras áreas que estudam o homem, de individualização e humanização da assistência.

1. Auxiliar de Ensino do Departamento de Enfermagem da Universidade de Londrina, PR.

2. Professor Assistente do Departamento de Enfermagem da Universidade de Londrina, PR. 
A Enfermagem, como profissão, sofre os reflexos desse movimento e passa hoje por um processo de auto-avaliação, onde seus profissionais buscam a definição de uma metodologia de assistência mais planejada, mais individualizada e que atenda o paciente considerando seus três planos: vital, psicossocial e existencial.

E o que se observa na assistência de enfermagem aos pacientes ditos "terminais"?

Entende-se por pacientes terminais não apenas os pacientes agonizantes, mas todos aqueles portadores de enfermidades que, mais ou menos rapidamente, evoluem para o óbito (D'ASSUNÇÃO, 1984).

Num estudo sobre "O Adoecer e a Morte", BASTOS (1983) afirma que o crescimento da $T a$ natologia (Thanatos $=$ morte, Logos $=$ tratado) deve-se mais a historiadores, filósofos e sociólogos que aos profissionais da saúde, os quais apresentam certo grau de dificuidade em lidar com esse assunto tabu. A morte, segundo esse autor, não é um evento puramente biológico, mas também psicológico, filosófico, social, religioso, ético, histórico, cultural e jurídico.

COSTA (1976) identifica duas posiçoes assumidas pelos enfermeiros frente às situições de morte iminente. Quando o paciente tem maior probabilidade de morrer, omitem-se do assunto morte e tendem a supervalorizar os cuidados físicos. Quando a possibilidade da morte se apresenta em siluações de emergência, mobilizam-se desveladamente expressando depois um sentimento de dever cumprido.

GUIMAR $\bar{E} S$ (1979) pergunla como ficaria a situação das enfermeiras frente à morte dos pacientes, se a maioria sente medo e angústia ao pensar em sua própria morte?

Alirma LOUZÃ (1982), que o trabalho com pacientes terminais provoca desestabilização emocional na equipe de saúde, desenvolvendo sentimentos que variam entre a culpa, depressão, tristeza, ansiedade e, até mesmo, identificação exagerada com o paciente, o que pode levar o profissional a uma confrontação com sua própria mortalidade.

KÜBLER-ROSS (1981) questiona se o fato da equipe de saúde concentrar-se nos equipamentos, pressão sanguínea, dados laboratoriais, não seria uma tentativa de rejeição da morte iminente, e de não ver o rosto angustiado do paciente que faz lembrar as limitações e a falta de onipotência dessa equipe.

Mas por que dirigir este trabalho, conforme pretendemos, para os pacientes cncológicos, se o câncer nem sempre é mortal? Por que escolher um hospital especializado em câncer para a realização deste traballıo?

NUNES (1980) descreve o câncer como um dos mais importantes símbolos da norte em nossos dias e afirma que somente quando os médicos (e as autoras incluem a equipe de saúde como um todo) integrarem sua própria mortalidade e abandonarem suas fantasias de onipotência, o trato diário com o paciente oncológico se tornará menos difícil.

WULLIEMIER (1980) relaciona o comportamento do canceroso com o simbolismo dessa doença que "devora por dentro" e descreve como causas do comportamento desajustado da equipe de saúde, os seguintes fatores: a identificação com o paciente, que faz com que o pessoal hospitalar seja invadido pelo seu próprio medo da morte; o sentimento de impotência diante da doença e o medo das perguntas dos pacientes.

Todavia, apesar de lodas as dificuldades, seria necessário que os profissionais de saúde não fugissem do envolvimento emocional com o paciente e faniliares, a fim de que o atendimento fosse menos frio e impessoal.

Mas como exigir que os membros de uma sociedade capitalista que diviniza a vida e "extingue" a morte passem a conviver placidamente com o morrer?

$A$ análise do antropólogo RODRIGUES (1983) sobre a morte nos levanta alguns pontos que merecem reflexĩo:

- Lixaltil-se a afirmaçĩo "ele nem sentiu que ia morrer", ao contrário de "sentiu a morte se aproximar".

- É importante que a morte seja "natural", porque a nalureza é calda vez mais dominada pelo homem, e por conseguinte, a morte também logo seria.

- A morte tem sempre um responsável: o erro do médico em não diagnosticar mais precocemente, a falta de incentivo à pesquisa para que a cura fosse logo descoberta ou a demora do paciente etn procurar o médico. Toda morte tem sempre um motivo, que poderia ter sido corrigido. Cria-se assim o mito da iniortalidade, ou como deline o autor, da a-mortalidade do homem.

- Ocultamos a morte de nossas crianças (talvez por considerá-la mórbida) e as presenteamos com canhões de brinquedo.

- Às crianças a quem eǹsinamos fisiologia sexual, línguas, computação, dizemos que o morto está dormindo ou foi viajar. 
Ainda segundo RODRIGUES (1983), devido à negação da morte que infesta a sociedade (e conseqüentemente a família), a morte foi transferida para os nospitais. Essa transferência pode, às vezes, ser justificada pelo desenvolvimento de técnicas médicas que exigem acompanhamento técnico, equipamentos, mas, por outro lado, cria um problema sério - o isolamento do paciente terminal de tudo quanto ele gosta ou valoriza.

No hospital impera a mentira institucionalizada, que a princípio tem a função de pre eger o paciente contra a angústia de sua morte, mas posteriormente essa mentira acaba por cumprir outro papel: o de fornecer à sociedade, família e equipe hospitalar uma "confortável ilusão, desobrigando-a de pensar na morte, permitindo a fuga de emoções".

Chega-se a um ponto em que a equipe de saúde, a família e o próprio paciente conhecem o diagnóstico, prevêem o desfecho, mas não conversam entre si. O médico espaça suas visitas, a enfermagem idem, não sabem como conversar, sentem-se impotentes. O paciente fica só com todos os seus medos, sem sentir apoio - e morre só, muitas vezes sedado.

Este trabalho pretende identificar os conceitos e reações da equipe de enfermagem frente ao paciente terminal - no caso do estudo, pacientes oncológicos, procurando ainda definir em que área de necessidades humanas está a prioridade na atuação desses profissionais. Pretende-se também definir quais as reações dos membros da equipe frente ao evento morte, reações estas que entendemos como determinantes do tipo de assistência prestada.

\section{METODOLOGIA}

Foi realizada uma pesquisa de campo, descritiva, no Hospital Professor Antonio Prudente (Londrina, PR), especializado na assistência a pacientes oncológicos, durante o primeiro semestre de 1984.

A população estudada é constituída de quarenta profissionais de enfermagem, assim compreendidos: seis enfermeiros, cinco bolsistas (estudantes do curso de Graduação em Enfermagem, que cumprem estágio remunerado na Instituição), dois técnicos de enfermagem, seis auxiliares de enfermagem e 21 atendentes de enfermagem, sendo todos funcionários nas unidades de internação, UTI, ambulatório e centro cirúrgico.
Os dados foram coletados através de entrevistas formais, realizadas no período de trabalho dos profissionais, pelas próprias autoras.

Os resultados obtidos serão apresentados em percentuais, não separados por categoria profissional, uma vez que o padrão das respostas foi uniforme.

\section{RESULTADOS E COMENTÁRIOS}

A caracterização da população, estudada por categoria profissional, sexo, idade, religião e tempo de formado, está descrita nas Tabelas 1 a 5.

TABELA 1 - População distribuída por categoria profissional.

\begin{tabular}{lr}
\hline Categoria & $\%$ \\
\hline Enfermeiro & 15,0 \\
Bolsista & 12,5 \\
Técnico de enfermagem & 5,0 \\
Auxiliar de enfermagem & 15,0 \\
Atendente de enfermagem & 52,5 \\
\hline Total & 100,0 \\
\hline
\end{tabular}

TABELA 2 - População distribuída por sexo.

\begin{tabular}{lc}
\hline Sexo & $\%$ \\
\hline Feminino & 77,5 \\
Masculino & 22,5 \\
\hline Total & 100,0 \\
\hline
\end{tabular}

TABELA 3 - População distribuída por faixa etária.

\begin{tabular}{lc}
\hline 'dade (anos) & $\%$ \\
\hline menos de 19 & 15,0 \\
$20 \longmapsto$ & \\
29 & 52,5 \\
$30 \longmapsto$ & 22,5 \\
$40 \longmapsto$ & 10,0 \\
\hline Total & 100,0 \\
\hline
\end{tabular}

Rev. Bras. Enf., Brasília, 37 (3/4), jul./dez. 1984 - 167 
TABELA 4 - População distribuída por religião.

\begin{tabular}{lr}
\hline Religião & $\%$ \\
\hline Católica & 72,5 \\
Protestante & 20,0 \\
Espírita & 5,0 \\
Messiânica & 2,5 \\
\hline Total & 100,0 \\
\hline
\end{tabular}

TABELA 5 - População distribuída por tempo de formada*.

\begin{tabular}{lr}
\hline Tempo de formado (anos) & $\%$ \\
\hline menos de 01 & 20,0 \\
& 14,3 \\
& 34,3 \\
10 & 22,9 \\
\hline \multirow{2}{*}{ Total } & 8,5 \\
\hline
\end{tabular}

- Foram exclurdos da Tabela 5 os bolsistas.
TABELA 6 - Tipo de assistência considerada prioritária no cuidado de enfermagem ao paciente terminal.

\begin{tabular}{lr} 
Tipo de assistência & $\%$ \\
\hline Enfocando plano físico & 5,0 \\
Enfocando plano existencial & 90,0 \\
Enfocando plano físico e existencial & 5,0 \\
\hline Total & 100,0 \\
\hline
\end{tabular}

Foi constatado que, apesar de a enfermagem centralizar a maior parte de suas ações no campo físico, apenas $5 \%$ consideraŕam prioritários os cuidados físicos. A assistência religiosa foi lembrada por apenas $7,5 \%$ dos entrevistados. A resposta predominante teve várias justificativas, entre as quais: "Esses pacientes precisam muito mais da nossá alenção e carinho que de remédios."

Perguntando aos entrevistados se já lhes havia acontecido do paciente querer conversar sobre câncer, $17,5 \%$ responderam que não. Dos restantes, apresentamos na Tabela 7 as respostas à pergunta: "Conseguiu manter um diálogo sobre o assunto?"

TABELA 7 - Respostas à pergunta: "Conseguiu manter um diálogo a respeito do câncer com o paciente?"

\begin{tabular}{lr}
\hline Respostas & $\%$ \\
\hline 1. Sim & 45,5 \\
2. Não tem permissão do médico para conversar sobre o diagnóstico com o paciente & 36,5 \\
3. Não conversou para que o paciente não soubesse por esse diálogo o seu diagnóstico & 15,0 \\
(são contra falar o diagnóstico para o paciente) & 3,0 \\
4. Não saberia o que falar & 100,0 \\
\hline Total & \\
\hline
\end{tabular}

É importante ressaltar que dos $45.5 \%$ dos entrevistados que conseguiram conversar sobre o câncer com seus pacientes, apenas $12,5 \%$ declararam ter se sentido tranqüilos durante o diálogo. Os $33 \%$ restantes verbalizaram sentimentos de tristeza e dificuldade em conversar.

Pode-se depreender dos depoimentos que a dificuldade reside no como conversar. Não existe nenhum tipo de sistemática de abordagem aos pacientes. Obviamente não se pode exigir um comportamento estático, aplicável a todos os pacientes, porém deveria haver para esses profissionais algum treinamento sobre abordagem, a fim de que os diálogos fossem mais produtivos e menos reticentes.

A maior concentração de informações recebidas recaiu sobre o item "câncer" e o enfoque, segundo as respostas, era dado sobre medidas terapêuticas.

Quando perguntados se haviam recebido 
informaçøes sobre assistência de enfermagem ao paciente terminal, vários entrevistados relataram ter recebido informações sobre preparo do corpo, o que não foi considerado resposta positiva pelas autoras.

Um questionamento a ser levantado sobre os resultados dessa tabela: Como pode atuar satisfatoriamente um profissional que não recebeu informaçбes sistematizadas sobre o problema mais grave enf rentado na instituição onde atua?

Um dos entrevistados respondeu que perguntaria a todo mundo para confrontar as respostas, pois sabe que a sistemática da equipe é mentir
TABELA 8 - Respostas à pergunta: "Você já recebeu algùm tipo de informação científica sobre: Morte e morrer, câncer, assistência de enfermagem a pacientes terminais?"

\begin{tabular}{lccc}
\hline \multicolumn{1}{c}{ Respostas } & $\begin{array}{c}\text { Sim } \\
\%\end{array}$ & $\begin{array}{c}\text { Não } \\
\%\end{array}$ & $\begin{array}{c}\text { Total } \\
\%\end{array}$ \\
\hline Morte e morrer & 27,5 & 72,5 & 100,0 \\
$\begin{array}{l}\text { Câncer } \\
\begin{array}{l}\text { Assistência de enfermagem } \\
\text { a pacientes terminais }\end{array}\end{array}$ & 52,5 & 47,5 & 100,0 \\
\hline
\end{tabular}

TABELA 9 - Respostas à pergunta: "Se você estivesse com sinais e/ou sintomas de câncer, questionaria sobre seu diagnóstico? A quem perguntaria?"

\begin{tabular}{lr}
\hline Respostas & $\%$ \\
\hline Não gostaria de saber & 12,5 \\
Perguntaria ao médico & 52,5 \\
Perguntaria ao médico ou enfermeira & 5,0 \\
Perguntaria à enfermeira & 22,5 \\
Perguntaria para quem soubesse ser mais sincero & 5,0 \\
Perguntaria para todos (para checar as respostas) & 2,5 \\
\hline Total & 100,0 \\
\hline
\end{tabular}

para o paciente. E o paciente? Não conseguirá ele também as respostas que deseja, confrontando as mentiras diferentes que receberá dos membros da equipe de saúde?

Perguntando aos quarenta entrevistados se jí lhes aconteceu de un paciente agonizante solicitar que permanecessem junto a cle, apenas très responderam nâo. Dos 37 que passaram pela experiência, apenas dois não atenderam à solicitação dos pacientes alegando falta de tempo. Os 35 restantes definiram seus sentimentos com relação ao ocorrido conforme discriminado na Tabela 10.

A justificativa "lalta de tempo" colocada por dois dos entrevistados, foi levantada também por alguns, como justificaliva de não poder se dar lanto tempo para as conversas de "pé de leito" como achariam necessário.

TABELA 10 - Respostas à pergunta: "Como se sentiu ficando junto a um paciente agonizante?"

Respostas

Sentimento de impotência

Sentimento de tristeza, depressão

Sọntimento de compaixão

Sentimento de desorientação quanto à melhor atitude a ser tomada

Sentimento ruim, de desconforto com a situação

Sentimento de dever cumprido, de ter ajudado

Nenhum sentimento 
Os entrevistados que responderam expressando sentimentos de dever cumprido, explicaram esse sentimento vagamente, sem conseguirem definir o porquê da certeza de terem ajudado.

A impotência colocada em $22,9 \%$ das respostas revela que nĩo só os médicos têm o mito da onipotência calcado em sua formaçĩo. Parte da equipe de enfermagem padece do mesmo mal. Seria importante lembrar que a atuação da enfermagem não é só na recuperação da saúde, mas também no proporcionar uma morte tranqüila, quando essa recuperação da saúde já .ã̃o é mais possível.

TABELA 11 - 0 paciente terminal deve ser esclarecido quanto ao seu diagnóstico?

\begin{tabular}{lc}
\hline Respostas & $\%$ \\
\hline Sim & 67,5 \\
Não & 32,5 \\
\hline Total & 100,0 \\
\hline
\end{tabular}

Algumas das justificativas da ıesposta NÃO:

- "Contar o diagnóstico para o paciente pode desesperá-lo e ele tentar suicídio. A gente mata o paciente de nervoso."

- "Não existe ninguém preparado para saber que tem câncer. Você pode accitar ter uma doença do coraç̃̃o, da cabeça, mas não aceita o câncer."

- "Mesmo que ele desconfie, a esperança é grande, nós não podemos tirar do paciente a esperança de cura".

- "Depois que conta é pior que na hora, porque a gente não sabe como levar a conversa depois".

Algumas justificativas da resposta SIM:

- "Dizem que é contra a ética contar o diagnóstico para o paciente, mas é contra a minha ética mentir".

- "Quando o paciente não sabe o que tem, cada pequena melhora é um abandono de tratamento."

- "Mais cedo ou mais tarde o paciente acaba descobrindo".

- "Quando o paciente sabe o que tem se cuida mais, accita mellıor o tratamento."

- "O diálogo fica muito mais franco, sem disfarces."

TABELA 12 - Respostas à pergunta: "Qual o significado da doença câncer para você?"

Uma doença como outra qualquer

Encara com esperança de cura

Sofrimento

Sofrimento e morte

Morte

Uma coisa da pior espécie, não tem objetivo

Tenebrosa, desfigurante, é o apodrecimento em vida

Apenas $10 \%$ dos entrevistados encara o câncer com relativo otimismo. A esmagadora maioria de $90 \%$ coloca o câncer como u'ma doença especial, geradora de morte, sofrimento e mutilação. Essa é também a caracterização que NUNES (1980) faz do câncer. Segundo a autora, essa doença representa essa tríplice ameaça, e mesmo que ela nem sempre mate, mutile ou provoque sofrimento, a imagem criada é a de "logotipo da morte".

Alguns entrevistados verbalizaram sentimento de medo com relação à morte como passagem, demonstrando relativa confiança numa vida pos- terior melhor que a atual. Mesmo com essa fé, sentiam medo da passagem, medo de sofrer dores.

Duas entrevistadas que demonstraram aversão a velórios, definiram essa aversão em relação ao morto e não ao ambiente do velório. Uma delas colocou: "Aqui no hospital a funerária desaparece com o morto. Deveria ser assim também fora daqui". Esse tipo de aversão ao cadáver, às manifestações da morte, à tanatomorfose é entendida por RODRIGUES (1983) como negação da morte: "fazer sumir o morto, banir a morte, conservar a ilusão de vida através da abolição da noção de morte..." 
TABELA 13 - Respostas à pergunta: "O que significa morte para você?"

Passagem para uma nova vida, melhor que esta

É sempre uma perda irreparável

Declararam 45\% dos entrevistados, encarar a morte profissionalmente da mesma mancira como encaram-na como pessoas, quando existe apego ao paciente. Houve ainda quem diferenciasse a visão de morte "profissional" e "pessoal", alegando encarar a morte dentro do hospital como um alívio do sofrimento.

Muito se falou, na introdução do trabalho, a respeito da confrontação da equipe de saúde com sua própria mortalidade, quando lidam com pacientes terminais. Fazendo a correlação com as respostas dadas sobre o conceito de morte, poderia-se levantar outro questionamento importante: como podem os profissionais de enfermagem proporcionar uma assistência eficaz na área psicoespiritual ou existencial se ainda não resolveram seus próprios conflitos nessa área?

TABELA 14 - Respostas à pergunta: "Você já pensou a respeito de sua própria morte?"

\begin{tabular}{lc}
\hline Respostas & $\%$ \\
\hline Sim & 82,5 \\
Não & 17,5 \\
\hline Total & 100,0 \\
\hline
\end{tabular}

É importante ressaltar que esses $17,5 \%$ dos entrevistados que nunca pensavam a respeito de sua própria morte se incluem tanto no grupo dos que aceitam a morte com "naturalidade", como no dos que têm sérios problemas em aceit'́-la. Os que responderam SIM à pergunta da Tabela 14 , revelaram ño aceitação e conflito na sua maioria $(63,6 \%)$

As autoras conseguiram, com as entrevistas, delinear uma linha de comportamento dentro da instituição que será relatada em seguida.

\section{CONCLUSÃO}

Buscando correlacionar os dados obtidos, foi construído o gráfico seguinte, que analisaremos descrevendo o porquê das influências de um dado sobre o outro e como essa reação en. cadeia poderia ser rompida.

As autoras consideraram a "falta de informações científicas sobre a morte e o morrer" como determinantes de toda a problemática representada no gráfico. Por quê?

Num estudo realizado neste mesmo hospital, HADDAD (1983) enfatizou a necessidade de "grupos de apoio", onde os enfermeiros que prestam assistência a pacientes terminais discutem com psicólogos as angústias e ansiedades que surgem no trato diário com esses pacientes.

Concordamos com o parecer da autora sobre a necessidade dos "grupos de apoio" e de uma equipe de psicólogos atuando concomitantemente junto aos pacientes e à equipe de saúde, porém acrescentaríamos mais duas necessidades a serem satisfeitas para se amenizar mais eficazmente o problema: a discussão sobre morte também com enfoque sociológico e filosófico, com toda a equipe de enfermagem, e o treinamento dessa equipe em técnicas de abordagem.

A Morte e o Morrer devem ser entendidos como duas coisas distintas. A morte é uma incógnita. Não a podemos estudar uma vez que não 


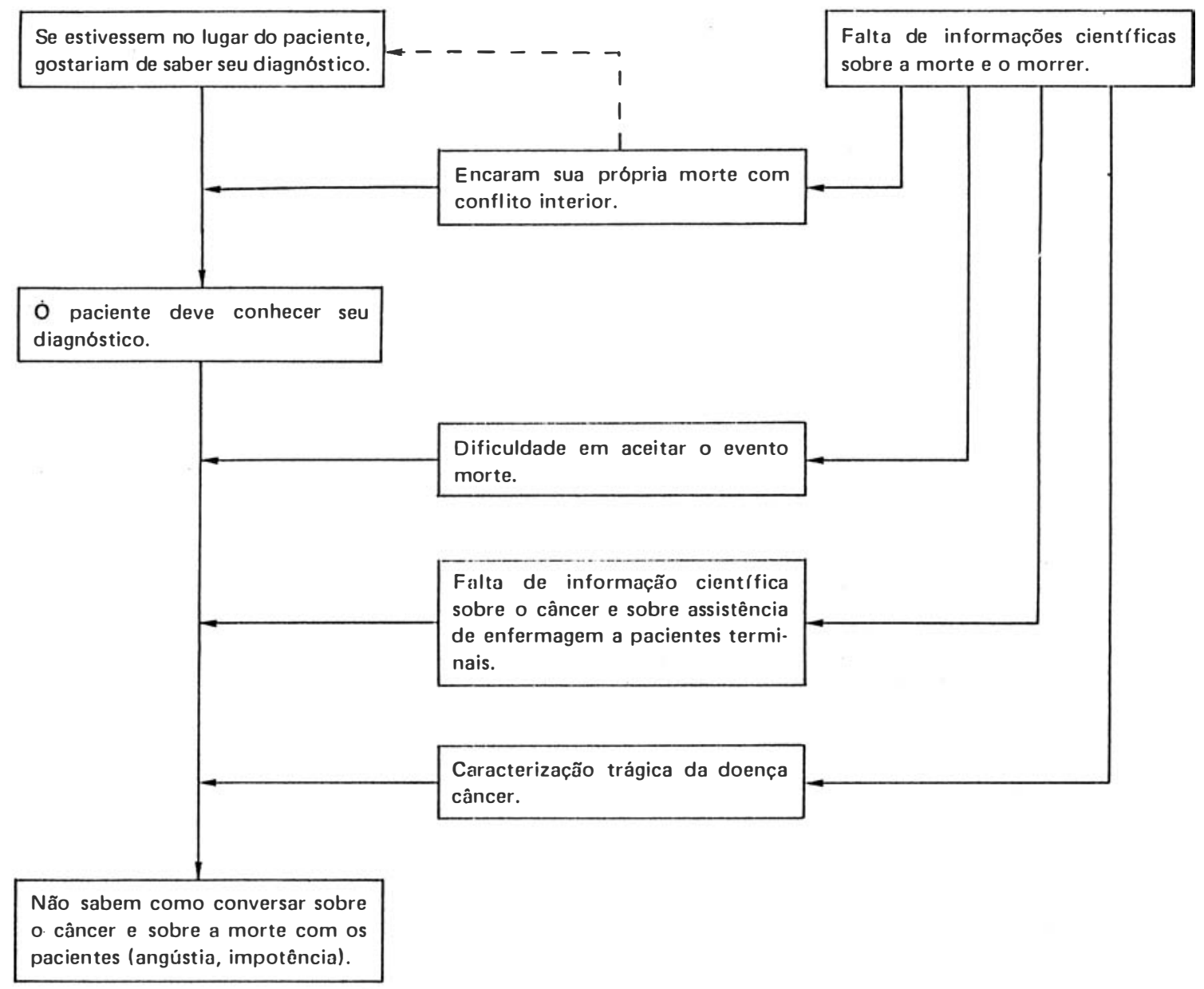

podemos nem sequer pensí-la. Como bem defïnc RODRIGUES (1983), "atravćs de que meios poderia um ser pensante pensar sua condiçiōo de não-pensante? A que tipo de lógica recorreria um existente para pensar a não-existência, se o próprio ato de pensar é a mais palmar rejeição do objeto pensado?"

Estudamos, portanto, os reflexos da morte. Reflexos no inter-relacioiamento de pessoas, na alteração da composição social dos grupos. A problemática maior passa a ser a ausência de um ser e as conseqüências dessa ausência. Morte é,-portanto, um evento principalmente sociológico, psicológico, filosófico, e os elementos dessas três ciências devem compor o que denominamos "inlormaçбes cient íficas sobre a morte".

E o morrer? Como se definiria?

Curiosamente, o medo mais vezes expressado nas entrevistas não diz respeito ao depois da mor- tc, $(50 \%$ dos entrevistados acredita numa outra vida mellıor, depois des(a), mas ao "antes".

O medo maior é o do sofrimento, da agonia, da dor lísica. Esse ć um medo que dificilmente se conseguiria eliminar dos pacientes ou da equipe, uma vez que é, simplesmente, uma manifestação do nosso instinto de sobrevivência. Podèmos sim, tentar atenuá-lo.

Um inciv'duo que já percorreu as cinco fases da morte definidas por KÜBLER-ROSS (1981), encontrando-se na última, a da aceitação, terá esse medo bastante atenuado, porque a ele não estarão somadas as angústias de tarefas inacabadas, de revolta, de negação da morte.

É neccssírio, portanto, auxiliar o paciente terminal a chegar na fase de aceitação, e, para isso, não só é necessário o conhecimento dessas cinco fases, mas também o treinamento de toda a equipe de enfermagem, e não só dos enfermeiros, em como fazer as conversas "ao pé do leito". 
Como indicação possível, a técnical de Relação de Ajuda, definida por LOFFREDI (1980) como "relaçбes facilitadoras que favorecem a liberação de uma atitude consciente, que permite ao indivíduo aprender a enfrentar suas dificuldades".

O treinamento do como falar e ouvir e a discussão e reflexão do que falar aos pacientes e porque falar, no entender das autoras, conseguiria diminuir a ansiedade da equipe de saúde quanto ao cuidado dos pacientes terminais, no caso em estudo, dos oncológicos. Conseguindo-se êxito nessa tarefa, o convívio com a morte passaria a ser fator de crescimento pessoal dos membros da equipe e não uma fonte de angústias e desajustamentos.

CHIIIDA, M.L.C. \& CRISTOFOLLI, D.A.S. Nursing team and the problematic of personalized assistance of terminal patients. Rev. Bras. Enf., Brasília, 37 (3/4): 165-173, Jul./Dec. 1984.

\section{REFERENCIAS BIBLIOGRÁFICAS}

BASTOS. O. O adocecr c a mortc. J. Bras. Psiquiat., Rio de Janciro. 32 (4): 211-218, 1983.

COSTA, L.A.T. Situações vida e morte: participação do cnfermeiro. Rio de Janeiro, 1976. (Disscrtação de mestrado - Escola de Enfermagem Ana Nery da URFJ).

D’ASSUMPÇÃO, E.A. Tanatologia e o paciente terminal. Diálogo Méd., Rio de Janciro, 10 (2), 1984.

GUIMARĀES, N.O. et alii. Morte: um desalio de cnfermagem. In: CONGRESSO BRASILEIRO DE ENIFERMAGEM, 31, Fortaleza, 1979. Anais: Brasília, ABEn, s.d.

HADDAD, M. do C.L. A importância do apoio psicológico aos enfermeiros que assistem pacientes terminais. Londrisa, Hospital Prolessor Antonio Prudente, 1983. (mimcograliado).
HORTA, iv. de A. Processo de enfermagem. São Paulo, I:PU, 1979.

KUBLER-ROSS, E. Solre a morte e o morrer. São Paulo, Martins Fontes, 1981.

LOFFREDI, L.E. Relação de ajuda. In: CONGRESSO BRASILEIRO DE ENIELRMAGEM, 32, Brasília, 1980. Anais. Brasília, ABEn, s.d.

LOUZĀ, J.R. \& LOUZ̄ NETO, M.R. O hospital c a mortc. Rev. Paul. Hosp., São Paulo, 30 (7/8): 172$177,1982$.

NUNISS, C..H.P. Relaçĩo médico-paciente cm cancerologia. J. Bras. Psiquiat., Rio de Janeiro, 29 (3):199202, 1980.

RODRIGUES, J. C. Tabu da morte. Rio de Janeiro, Achiamé. 1983.

WHULL.IlEMIL:R, l'. Assistência psíquica c cancerosos. Documento Roche, São l'aulo, (4): 83-87, abr. 1980. 